\title{
Product Line Extension among New England Craft Breweries
}

\section{Joshua Berning and Michael McCullough}

\begin{abstract}
The U.S. brewing industry was at a low point in the 1980s. Since that time, more than 4,000 new breweries of varying scales and scopes have entered the market. Given the rapid expansion in this industry, which involves large capital costs, it is useful to consider the competitive nature of individual firms. Using a sample of New England breweries, this study identifies several firm and geographic attributes that are linked to firms' product offerings. We find that the breadth of product lines and nature of competition varies by brewery type and by the economic environment of the market.
\end{abstract}

Key Words: brewing industry, economies of scope, product differentiation

Breweries are classified according to their ownership structure and the volume of beer they produce annually. Craft breweries are "small, independent, traditional" breweries that emphasize the quality of their products over the quantity (Brewers Association 2013), and a generally accepted classification for craft breweries is barrel production (a barrel is equivalent to 31 gallons) of six million or less per year. Breweries classified as micro produce 15,000 barrels or less per year. At that scale, craft breweries do not approach the minimum efficient scale of production of large macro producers that brew considerably more than 6 million barrels per year (Tremblay and Tremblay 2005). In addition, the U.S. brewing industry is characterized by large barriers to entry related to economies of scale in production, marketing, and distribution of products (Porter 1980, Tremblay and Tremblay 2005). Brewing vats, bottling and kegging lines, and especially fermentation tanks require a large amount of start-up investment and occupy a good deal of space.

Joshua Berning is an associate professor in the Department of Agricultural and Applied Economics at University of Georgia. Michael McCullough is an associate professor in the Agribusiness Department at California Polytechnic State University. Correspondence: Joshua Berning - 208 B Conner Hall - Department of Agricultural and Applied Economics " University of Georgia - Athens, GA 30602 - Phone 706.542.0768 - Email jberning@uga.edu.

The authors received helpful comments from seminar attendees at the Agricultural and Applied Economics Association annual meeting in Minneapolis, Minnesota, and the Food Distribution Research Society annual meeting in Salt Lake City, Utah. We also received helpful comments from Trey Malone, Jayson Lusk, and seminar attendees in the Department of Agricultural Economics at Oklahoma State University. We thank an anonymous reviewer and the editor, David Abler. We also thank Steven Feeney and Elise Johnson for their help with data collection and Baxter Panola for his input. All mistakes are solely the authors' responsibility.

The views expressed are the authors' and do not necessarily represent the policies or views of any sponsoring agencies.

Agricultural and Resource Economics Review 46/1 (April 2017) 73-86

(C) The Author(s) 2016. This is an Open Access article, distributed under the terms of the Creative

Commons Attribution licence (http://creativecommons.org/licenses/by/4.0/), which permits unrestricted re-use, distribution, and reproduction in any medium, provided the original work is properly cited. 
Furthermore, many states prohibit direct sales by breweries, requiring them to sell through independent wholesalers, which adds another transactional barrier.

Despite the many challenges, the craft segment of the beer industry has experienced significant growth over the past 20 years even as larger brewers have seen decreasing sales (Redding 2013). In 2014, there were more than 3,000 craft breweries in the United States, the most since the 1870s, and approximately 1,000 additional breweries were added in 2015 (Brewers Association 2015). Because craft brewers cannot compete with macro brewers in terms of volume, they tend to offer a wide variety of products to satisfy ever-evolving consumer tastes. Thus, it is informative to consider how craft breweries develop their product offerings and compete for market share.

Product proliferation has important impacts on firms' market power, which can affect the conduct and performance of firms in the brewing industry (Tremblay and Tremblay 1996). In particular, product line proliferation can deter potential entrants, thus limiting competition and product diversity (Schmalensee 1978, Scherer 1979). On the positive side, product proliferation can provide welfare benefits for variety-seeking consumers as long as prices for the various products do not significantly rise. It also can generate economies of scope (Baumol, Panzar, and Willig 1982), which can reduce a firm's average cost of production and risk of excess capacity and potentially create interdependence of brands (Tremblay and Tremblay 1996). Finally, product proliferation is important in terms of marketing; understanding how firms develop product line strategies can provide insight into how relatively small firms can compete in industries that present similarly large barriers.

For our analysis, we gather data on product offerings by craft breweries in the New England area and the characteristics of those breweries and the surrounding economic region. We determine the total number of beer products available in 2013 and how many of those products were core products that were brewed year round versus seasonal beers that were produced periodically in relatively small batches. Using a structural model of firm behavior and findings from previous studies, we estimate how characteristics of the firms and the geographic region affect each firm's degree of product differentiation. Our estimates point to several links between those characteristics and the number of core and seasonal beers offered that drive both product proliferation and specialization by craft breweries. Furthermore, certain types of market environments lend themselves to more-diverse sets of firms.

\section{Motivation}

Large U.S. macro breweries are widely known for their flagship or core ${ }^{1}$ brews such as Budweiser, Miller Lite, and Coors. These are mass produced beers

1 Core refers to beers that are produced year round; flagship is a core beer with strong sales. 
benefitting from scale economies and extensive distribution in every market in the United States. Economies of production not only reduce prices for consumers but also allow brewers to offer consistent quality over time and distance. Craft brewers, on the other hand, produce on smaller scales, usually market a greater variety of styles of beer, and often experiment with ingredients. This has resulted in a revival of beer culture in the United States (Goldfarb 2014), and the diversity of products is exciting for consumers and the beer industry in general.

A study by Tremblay and Tremblay (2005) identified several potential benefits of product differentiation for brewers. First, since variety in a product line behaves as a normal good, a brewery with an extensive product line could see an increase in total demand for its products. In addition, there could be demand interdependencies between existing brands and new offerings, which could boost a firm's market share. Importantly, product diversity can reduce the risk of loss of sales from unexpected changes in consumer demand and help brewers avoid excess capacity. From a cost perspective, producing several product lines can generate economies of scope as well, particularly when several beers share similar production processes. Finally, by providing a variety of beers, craft breweries might deter other breweries from entry into specific niches. For example, a brewery might be less likely to offer a double-IPA (India pale ale) if another brewery already has a successful double-IPA in the same market.

Tremblay and Tremblay (1996) generalized the product-differentiation decision. Consider a firm that produces one product, $a$, with quantity $q$, price $p$, and total cost $C$. Its profit for the product is $\pi_{1}=p_{a} q_{a}-C_{a}$. Extending the product line by one product $(b)$ provides increased revenue and a greater cost such that its new profit is

$$
\pi_{2}=p_{a} q_{a}^{*}+p_{b} q_{b}-\left(C_{a}+C_{b}-\theta\right)
$$

where $\theta$ represents the potential economies of scope associated with adding a second product. It is important to remember that addition of a second product could also create diseconomies of scope due to excess capacity. We extend the Tremblay model by redefining demand for the existing product: after the firm adds the new product, $q_{b}$, demand for the existing product becomes $q_{a}^{*}$. If addition of product $b$ increases market share by making the brand more attractive, $q_{a}^{*}>q_{a}$. Alternatively, product $b$ could cannibalize market demand, resulting in $q_{a}>q_{a}^{*}$.

Intuitively, if the added revenue exceeds the added cost, product extension will occur. Specifically, extension occurs when $\pi_{2}>\pi_{1}$ or

$$
\left[\left(q_{a}^{*}-q_{a}\right) p_{a}+p_{b} q_{b}\right]-C_{b}+\theta>0 .
$$

Thus, we can see that the firm's decision to extend its product line comes down to whether adding the new product generates enough additional revenue to 
cover the additional cost of creating and maintaining it net of any economy of scope (Watson 2009). Importantly, it is also necessary for

$$
\pi_{2}>p_{b} q_{b}^{*}-C_{b}
$$

where $q_{b}^{*}$ is demand for the new product when it is the firm's only product. That is, it must also be less profitable for the firm to drop its original product, $a$, and exclusively carry the new product.

As can be seen from equations 1 and 2, the brewer's decision to expand its product line is a function of total demand for both products, the product costs, and potential economies of scope. As an extension to this simple framework, we also consider other market factors that could affect the firm's decision to expand its product line.

\section{Industry Clusters}

The tremendous expansion of the craft brewing industry over the past 30 years also led to extensive product differentiation and introduction of a number of styles of beer never before brewed in the United States (Mitchell 2015). As additional breweries continue to emerge in an area, this could lead to an increase or decrease in the extent of product differentiation. Studying the market for eyeglasses, Watson (2009) noted that, in response to an increase in the number of rivals, firms' product varieties first rose and then declined. He suggested that this was a product of a tradeoff between beneficial clustering effects and business stealing.

In the case of breweries, an increase in the number of craft breweries in a given geographic region could lead to increased product variety for several reasons. First, we have observed that the industry is characterized by a pervasive camaraderie. There is considerable anecdotal evidence of craft brewers working together to help the industry as a whole rather than competing with each other. ${ }^{2}$ Such cohesion could build and maintain human capital that might be essential for development of successful product lines. Furthermore, a large number of breweries engage in collaborative brewing efforts in which two or more breweries work together to produce a single co-labeled beer. Such efforts suggest that the particular environment of the craft beer industry could have a positive impact on the extent of product line differentiation.

\footnotetext{
2 Samuel Adams Brewing's American Dream Program is a prime example of such philanthropic and cooperative programs. It assists new, small businesses in the food, beverage, hospitality, and craft brewing industries to identify lenders and other forms of business advising (http://btad. samueladams.com).
} 
Potential economies of agglomeration may also emerge in areas where more than one brewery is operating, forming an industrial cluster. Such economies occur when it is less costly for two or more breweries to produce their product lines in one defined industrial cluster rather than producing them in economically separate clusters (Goldstein and Gronberg 1984). When that is the case, it may be more cost-effective to brew a relatively large number of kinds of beer. This approach to production would affect the costs presented in equations 1 and 2 but the effect would be indirect rather than direct.

A larger number of brewers could also lead to increased competition and thus to a greater number of products offered as a way to differentiate one firm from another. Such clusters of competitors can drive individual firms to become more innovative (Love and Roper 2001, Porter 1990).

While the provision of variety is welfare-enhancing in general, there is a limit to the number of varieties that can effectively occupy a market. Extensive variety offered in a geographic region can deter new entrants and incumbents considering expanding their product lines.

Although craft breweries distribute outside their immediate geographic locations, they generally cater to their local clienteles first. A regional brewer we spoke to, for example, described a key marketing objective as selling the premier IPA beers in the region. The owner of a small micro brewery with whom we spoke aimed to win the local city market first. In both cases, the breweries wanted to establish a strong local consumer base before expanding their target markets and therefore were competing on a smaller scale with other craft brewers in the area. In a restricted geographic area, product saturation can occur relatively quickly and have an immediate dampening effect on expansion of the variety of products.

Expansion of the number of breweries in a region could further incentivize brewers to produce fewer products. For example, a craft brewer might choose to focus on a smaller, higher-quality product line and avoid an extensive product offering. An emphasis on quality craftsmanship is not uncommon in the industry. The Alchemist in Vermont, for example, originally brewed multiple styles of beer but chose to focus solely on its award-winning Heady Topper. The website notes that they are "currently focused on brewing one beer perfectly" (emphasis added). Brewers can also choose to produce beers that occupy one particular regional niche and avoid their competitors' niches altogether, thus preventing greater future competition that could drive down their profits.

\section{Data}

We created a unique data set of breweries located in the six New England states in spring, 2013, using the Brewers Association database of all craft breweries by state. We then verified each brewery's existence using online sources, including websites and other industry-related databases, creating a final sample of 111 craft breweries. While we cannot guarantee that the list is exhaustive, it is 
similar to U.S. Census data, which reported 100 brewery establishments (North American Industry Classification System (NAICS) code 312120) in New England in 2013. The census data are based on multiple sources and can be subject to non-sampling errors that generally result in smaller counts of establishments than expected. ${ }^{3}$ Using the breweries' websites, we collected data on how long the breweries had been in operation and their product offerings. In addition to the number of beer products each brewer sold, we determined how many were core beers and how many were limited seasonal offerings.

The Brewers Association also categorized the breweries by their scope of operations as micro, regional, or contract. Micro breweries produce fewer than 15,000 barrels per year and sell 75 percent or more of their beer offsite-this is in contrast to brewpubs, which sell more beer onsite and sell food items. Regional breweries offer a larger number of traditional craft beers but only produce between 15,000 and 6 million barrels annually. Contract brewers either produce beer for other firms or have beer brewed for them by other breweries. These types of breweries face different cost structures and can generate different economies of scope.

We also identified breweries that, to date, had won a World Beer Cup (WBC) award. The WBC is an international competition created by the Brewers Association in 1996 and held annually to honor the top three beers in each of 91 categories. A WBC award is generally viewed by craft brewers as a pinnacle of achievement.

We gathered census data on the population, median income, and median household rent in each city in which a brewery was located to identify regional demographic characteristics. Median household rent is used as a measure of local real estate costs but some of the cities report no rental housing.

Looking at the sample summary statistics (Table 1), we note that the breweries tended to offer more seasonal beers than core beers. In fact, one brewer offered 27 seasonal beers and only 6 core beers. Some breweries offer only core beers (45 of 111), providing little variation throughout the year, and a few (5 of 111) offer only seasonal beers, providing a more varied product offering throughout the year.

Our sample included 17 contract breweries, 81 micro breweries, and 13 regional breweries, and 35 percent (39) had a tasting room. The average age of the breweries was twelve years, suggesting mature establishments. Interestingly, one of the breweries was 124 years old. When we removed that brewery from the sample, the average age was still 11.2 years. While the average number of WBC awards was 0.32 , only nine breweries had won a WBC award; one of the breweries had won the award twelve times and six had won the award more than once.

3 A discussion of these errors can be found at www.census.gov/econ/susb/introduction.html. 
Table 1. Summary Statistics

\begin{tabular}{lrrrr}
\hline Variable & Mean & Std. Dev. & Min. & Max. \\
\hline Flagship brews & 3.58 & 2.82 & 0.0 & 17.0 \\
Seasonal brews & 3.99 & 5.53 & 0.0 & 27.0 \\
Tasting room (n=39) & 0.35 & 0.48 & 0.0 & 1.0 \\
WBC award & 0.32 & 1.59 & 0.0 & 12.0 \\
Age of brewery & 12.23 & 13.88 & 0.0 & 124.0 \\
Population (thousands) & 38.67 & 68.75 & 0.5 & 380.4 \\
Median income (thousand dollars) & 51.74 & 29.12 & 14.7 & 159.7 \\
Household rent (median, dollars) & 752.71 & 428.37 & 0.0 & 2000.0 \\
Contract brewer (n=17) & 0.15 & 0.36 & 0.0 & 1.0 \\
Micro brewer (n=81) & 0.73 & 0.44 & 0.0 & 1.0 \\
Regional brewer (n=13) & 0.12 & 0.31 & 0.0 & 1.0 \\
Brewery LQ & 6.55 & 14.77 & 0.0 & 98.5 \\
Winery LQ & 1.09 & 4.86 & 0.0 & 40.3 \\
Wholesaler LQ & 1.00 & 2.90 & 0.0 & 16.0 \\
Bar LQ & 1.28 & 1.71 & 0.0 & 14.1 \\
\hline
\end{tabular}

To examine the impact of other craft breweries on a brewery's decision to extend its product line, we calculated location quotients (LQs) for breweries in each city using census zip-code business pattern data aggregated at the city level:

$$
L Q=\frac{F_{i m}}{F_{j m}} / \frac{F_{i n}}{F_{j n}}
$$

where $F$ is the total number of firms in industry $i$ (breweries) and $j$ (all industries) for city $m$ and county $n$. Thus, the LQ effectively provides a measure of the percentage of breweries in a city relative to the percentage of breweries in the respective county. The LQ value is greater than or equal to 0 , and an LQ greater than 1.0 indicates that the density of breweries in the city is greater than the density of breweries in the county. As shown in Table 1, most of the cities in our data set had a greater density of breweries than the county in which they were located. Some cities reported no breweries and therefore had an LQ of 0 . As previously noted, this was likely due to non-sampling errors associated with how establishments were counted in the census. As a result, the LQ introduces some bias into the analysis via measurement error.

We also created LQs for three related industries: wineries (NAICS 31213), beer wholesalers (NAICS 42481), and bars (NAICS 72241). Wineries provide a substitute good and may act as competitors for breweries. Wholesalers and bars 
are part of the brewery supply chain and can promote expansion of a brewery's local market penetration. The average density of wineries in cities was roughly similar to the density of wineries in the respective counties, although some cities had much higher densities of wineries. The LQs calculated for wholesalers and bars in the cities and respective counties were generally similar. There was much less variation in LQs for wholesales and bars than for breweries.

\section{Empirical Model}

We examine firm and location characteristics that are likely to affect a firm's decision to extend its product line based on equations 1 and 2. Our empirical specification is

$$
\operatorname{count}_{i}^{j}=f\left(X_{i}, \delta\right)+\varepsilon_{i}
$$

where the dependent variable is a count of the number of types of beers offered by brewery $i$. We specify the variable using three categories: $j=$ total, core, and seasonal. We also include several brewery characteristics $(X)$ that may affect the brewery's decision to extend its product line: presence of a tasting room, receipt of a WBC award, number of years in operation, and classification as micro, regional, or contract. The term $\delta$ represents state-specific effects, and $\varepsilon_{i}$ is an error term.

The size of each firm will affect its cost structure $\left(C_{a}\right.$ and $\left.C_{b}\right)$ and ability to capitalize on economies of scope $(\theta)$. Relatively large breweries would have greater access to equipment, allowing them to potentially producer a larger line of products involving different technological requirements, and greater space and resources to manage multiple batches. ${ }^{4}$ We further capture relevant regional factors that could affect consumer demand using estimates of each city's population, median income, and median rental housing cost and LQs for several related industries as previously described.

We estimate equation 3 using a negative binomial maximum-likelihood model. A likelihood-ratio test of over-dispersion indicates that the negative binomial specification is preferred to the Poisson specification. To account for correlation between breweries, we cluster the errors based on the brewery size classifications.

A potential problem with our specification is endogeneity of a brewery's choice of location (Abraham, Gaynor, and Vogt 2007, Watson 2009) since brewers choose both where to operate and what products to offer. If unobservable characteristics are correlated with the location factors modeled

\footnotetext{
4 While all beers are made using the same basic ingredients (water, malt, hops, and yeast), different styles of beer can require different production techniques, additional ingredients for flavor, and different or additional grains for the mash (e.g., wheat).
} 
in equation 3, our estimates for $\beta$ will be biased. Abraham, Gaynor, and Vogt (2007) faced a similar problem when modeling entry of hospitals and provision of medical services. They addressed this concern by specifying a two-stage model; the first stage involved a Heckman-style selection model and the second stage used a structural model. Watson (2009) employed a two-stage model similar to a Heckman specification that corrected for the entry decision.

We followed the simplest approach and estimated a two-stage Heckman-style model. In the first stage, we estimated the probability that a brewer would locate its operation in any city in New England using a probit model. For the exclusion restriction, we used the ratio of all other industries other than breweries to all industries in each city-essentially, the density of other businesses in the city. This density could affect whether a brewer chooses to locate its operation in that city but would not affect the extent of its product line. In the second stage, we included the inverse Mills ratio from the first stage as a selection correction. Use of this correction approach did not change the results of the model, indicating that spatial selection was not a factor. Therefore, going forward, we discuss only the estimates from equation 3.

\section{Results}

We used equation 3 to generate estimates of each brewery's total number of beer products (Table 2), number of core beer products (Table 3), and number of seasonal beer products (Table 4) using several specifications. To improve our ability to interpret the results, we calculated the marginal effects for each model.

We find that brewery-specific characteristics have an effect on the length of their product lines (Table 2). Breweries that had a tasting room tended to offer about six more beers in their product line. Interestingly, the likelihood of having a relatively large number of products was less pronounced for core beers (see Table 3) and more pronounced for seasonal beers (see Table 4). Intuitively, a brewery that provides beer directly to the public through a tasting room could benefit more from offering a variety of beers rather than a standard set of beers that does not change. Patrons of tap rooms often expect offerings they cannot purchase elsewhere. In a cross-sectional data set, presence of a tasting room could be endogenous, but the decision about whether to offer a tasting room generally occurs when building the brewery whereas product line decisions can change at any time.

Winning a WBC award is associated with fewer total beers (Table 2), and the reduction comes primarily from core beers (Table 3 ). While this effect is small (approximately two fewer beers for a brewery winning ten awards), it suggests that breweries that win awards tend to have smaller product lines. The number of seasonal beers does not change significantly.

The age of a brewery has a modestly significant effect on the number of core beers offered. As breweries get older, they offer fewer core beers. However, this 
Table 2. Estimates of Change in Total Number of Beers Produced

\begin{tabular}{lcccc}
\hline & \multicolumn{4}{c}{ Model Number } \\
\cline { 2 - 5 } Variable & $\mathbf{1}$ & $\mathbf{2}$ & $\mathbf{3}$ & $\mathbf{4}$ \\
\hline Tasting room & $6.203^{* * *}$ & $6.131^{* * *}$ & $5.978^{* * *}$ & $6.470^{* * *}$ \\
WBC award & $-0.226^{* * *}$ & $-0.220^{* * *}$ & $-0.205^{* *}$ & $-0.139^{*}$ \\
Age & -0.0662 & -0.066 & -0.0666 & -0.0642 \\
Brewery LQ & & 0.0141 & 0.0148 & $0.0166^{* * *}$ \\
Winery LQ & & 0.0176 & 0.0258 \\
Wholesaler LQ & & & 0.212 & 0.168 \\
Bar LQ & & & 0.196 & $0.108^{* *}$ \\
Population & & & & $-0.00820^{* *}$ \\
Median income & & & & $-0.0229^{* * *}$ \\
Median house rent & & & & -0.000188 \\
Contract brewer & $-0.644^{* * *}$ & $-0.579^{* * *}$ & $-0.852^{* * *}$ & $-0.380^{* *}$ \\
Regional brewer & $7.626^{* * *}$ & $7.605^{* * *}$ & $6.977^{* * *}$ & $7.032^{* * *}$ \\
Observations & 111 & 111 & 111 & 111 \\
\hline
\end{tabular}

Notes: Standard errors are calculated using the Delta method. ${ }^{* * *} \mathrm{p}<0.01,{ }^{* *} \mathrm{p}<0.05$, and ${ }^{*} \mathrm{p}<0.10$.

Table 3. Estimates of Change in Total Number of Core Beers Produced

\begin{tabular}{lcccc}
\hline & \multicolumn{4}{c}{ Model Number } \\
\cline { 2 - 5 } Variable & $\mathbf{5}$ & $\mathbf{6}$ & $\mathbf{7}$ & $\mathbf{8}$ \\
\hline Tasting room & $1.310^{* * *}$ & $1.307^{* * *}$ & $1.260^{* * *}$ & $1.257^{* * *}$ \\
WBC award & $-0.163^{* * *}$ & $-0.162^{* * *}$ & $-0.165^{* * *}$ & $-0.197^{* * *}$ \\
Age & $-0.0236^{*}$ & $-0.0236^{*}$ & $-0.0239^{*}$ & $-0.0247^{* *}$ \\
Brewery LQ & & 0.000904 & 0.00345 & 0.00647 \\
Winery LQ & & & $-0.0396^{* * *}$ & $-0.0381^{* * *}$ \\
Wholesaler LQ & & & -0.025 & -0.0267 \\
Bar LQ & & -0.0798 & -0.118 \\
Population & & & & 0.00204 \\
Median income & & & & $-0.0112^{* * *}$ \\
Median house rent & & & 0.302 & 0.000591 \\
Contract brewer & $0.297^{* *}$ & $0.303^{*}$ & $3.062^{* * *}$ & 0.469 \\
Regional brewer & $2.949^{* * *}$ & $2.949^{* * *}$ & 111 & 111 \\
Observations & 111 & 111 & & \\
\hline
\end{tabular}

Notes: Standard errors are calculated using the Delta method. ${ }^{* * *} \mathrm{p}<0.01,{ }^{* *} \mathrm{p}<0.05$, and ${ }^{*} \mathrm{p}<0.10$. 
Table 4. Estimates of Change in Total Number of Seasonal Beers Produced

\begin{tabular}{lcccc}
\hline & \multicolumn{4}{c}{ Model Number } \\
\cline { 2 - 5 } Variable & $\mathbf{9}$ & $\mathbf{1 0}$ & $\mathbf{1 1}$ & $\mathbf{1 2}$ \\
\hline Tasting room & $6.459^{* *}$ & $6.416^{* *}$ & $6.131^{* *}$ & $6.884^{* * *}$ \\
WBC award & 0.0104 & 0.0121 & 0.00304 & 0.0885 \\
Age & -0.0363 & -0.0358 & -0.04 & -0.0356 \\
Brewery LQ & & 0.00614 & 0.00826 & 0.00175 \\
Winery LQ & & $0.0366^{* * *}$ & 0.0436 \\
Wholesaler LQ & & & $0.258^{* * *}$ & 0.203 \\
Bar LQ & & & $0.347^{* * *}$ & $0.282^{* * *}$ \\
Population & & & $-0.0160^{* * *}$ \\
Median income & & & & $-0.0200^{* * *}$ \\
Median house rent & & & & $-1.624^{* * *}$ \\
Contract brewer & $-1.420^{* * *}$ & $-1.406^{* * *}$ & $-1.207^{* * *}$ \\
Regional brewer & $5.378^{* * *}$ & $5.363^{* * *}$ & $4.543^{* * *}$ & $5.004^{* *}$ \\
Observations & 111 & 111 & 111 & 111 \\
\hline
\end{tabular}

Notes: Standard errors are calculated using the Delta method. ${ }^{* *} \mathrm{p}<0.01{ }^{* *} \mathrm{p}<0.05$, and ${ }^{*} \mathrm{p}<0.10$.

effect may simply represent increased efficiency by the brewery; efficient breweries that produce fewer beers well might survive longer in the industry.

The results for the brewery LQs suggest that the number of beers offered by a brewer increases slightly as the density of breweries in the city rises. This effect is significant only for model four (Table 2). Based on the results for total beers produced (Table 2), an increase in the LQ from the average of 6.55 to the maximum of 98.5 results in 1.5 more beers offered by a brewery. While this effect is relatively small, it raises several important considerations. An increase in brewery density leads to an expansion in variety offered. This could suggest that increased firm entry generates increased competition; incumbent firms may expand their product lines to compete with new entrants or new entrants may enter dense markets with a greater variety of product offerings. Alternatively, as previously discussed, increased brewery density could spark greater collaboration or creativity by brewers to create a more vibrant craft-beer environment. Anecdotal evidence from the craft beer industry suggests that collaboration may be a stronger influence than competition (Hernandez 2012).

Interestingly, the density of wineries has a different effect. As the density of wineries increases, the total number of core beers produced by a brewery decreases (Table 3) and the number of seasonal beers produced increases (Table 4). Breweries could be competing with wineries by reducing their core brands and offering greater seasonal variety such as summer and pumpkin 
ales. The effect of wineries is small, suggesting that it occurs primarily in areas with a relatively high density of wineries.

We expected that a high density of wholesalers would lead to larger total product lines by brewers; instead, we found that the density of wholesalers only affected the number of seasonal offerings. The reason for this is not clear; it could indicate that a wholesaler provides marketing benefits to local breweries, allowing them to expand their product offerings with seasonal varieties. That is, by obtaining a reliable distribution network, the brewer can focus on making beer rather than sales.

Cities in which there are numerous bars are also associated with a greater number of product offerings, primarily seasonal products, by breweries. Bars are a key component in the distribution of craft beers. And given that all of the New England states allow craft brewers to distribute their products directly, bars may be more appealing than wholesalers that typically require a margin before delivering products to retailers.

We also estimated the models using quadratics of the LQs. While the quadratic terms were significant in several of the specifications, the net effect was economically insignificant in most cases. When it was economically significant, the interpretation of the results was the same as for those of the linear model. Thus, we do not report those results.

Contract brewers tended to offer slightly fewer total beers than micro breweries, although the difference was small. They also offered more core bears and fewer seasonal beers. These results are intuitive since contract brewers generally lack opportunities to experiment with new products.

Regional breweries, which produce a greater total volume than micro breweries, also produce much larger product lines on average (seven to eight beers) that consist of both core and seasonal beers. This suggests that the breweries in our sample tended to expand their product lines as their volume of production increased. Again, this is related to the idea that larger breweries can capture economies of scope when adding an additional product. Their ability to offer a larger product line may be tied to increased capital capacity and a greater ability to absorb failure of a new product than smaller breweries.

We find that both population size and income level are negatively correlated with the size of a brewery's product line in general and with the number of seasonal beers in particular. This is not consistent with expectations. If variety is a normal good, we expect a positive relationship with income. Similarly, since total demand should increase with the area's population, we would expect an increase in population to be associated with greater variety. It may be that these variables are endogenous to our model specification, and unobservable market characteristics are correlated with population and/or income, generating negative bias in our parameter estimates.

The effect of median household rent was not significant. However, seven of the breweries in the data set were located in cities with median household rents of zero so our estimates of the effect of household rent could be biased. 
We generated estimates using two versions of the model, one in which we excluded the household rent variable and another in which we dropped the observations with zero household rent values. Excluding the rent variable changed the results only minimally, and we exclude these results for brevity.

\section{Discussion}

Overall, our results indicate that some brewery and regional economic characteristics affect the product line length of breweries in the New England states. We also find differences when comparing core beers to seasonal beers. Further, we find that increasing density of competition seems to increase total variety, although minimally.

These preliminary results from a limited data set highlight potential avenues for future research. Information on product quality, for example, could allow for disaggregation of the product line offerings. Product quality could be evaluated horizontally (e.g., evaluating the various types of beers offered) or vertically (based on some rating system for quality). Various inputs could be considered as well, such as the types of malts and hops used in production.

We do not account for any dynamic changes in this model. At a basic level, this type of study would benefit from panel data. On a more sophisticated level, it would be useful to compare the effect of firm density for incumbent firms versus new entrants (Watson 2009).

Finally, as the craft beer industry continues to expand and develop, the marketing channels that supply beer will also change. In particular, distribution laws and the costs of distribution will affect how breweries compete in the future.

\section{References}

Abraham, J.M., M. Gaynor, and W.B. Vogt. 2007. "Entry and Competition in Local Hospital Markets." The Journal of Industrial Economics 55(2): 265-288.

Baumol, W.J., J.C. Panzar, and R.D. Willig 1982. Contestable Markets and the Theory of Industry Structure. New York, NY: Harcourt Brace and Jovanovich.

Brewers Association. 2013. "Craft Brewer Defined" web page. www.brewersassociation.org/ statistics/craft-brewer-defined (accessed September 2013).

—. 2015. "Number of Breweries" web page. www.brewersassociation.org/statistics/ number-of-breweries (accessed November 2015).

Goldfarb, A. 2014. "A Glorious Craft Lager Revival Is upon Us.” Esquire, April 12.

Goldstein, G.S., and T.J. Gronberg. 1984. "Economies of Scope and Economies of Agglomeration." Journal of Urban Economics 16(1): 91-104.

Hernandez, B. 2012. "What a Year: Looking Back on 2012." www.stonebrewing.com/blog/ philosophy/2012/what-year-looking-back-2012\#ageGate (accessed November 1, 2015).

Love, J.H., and S. Roper. 2001. "Outsourcing in the Innovation Process: Locational and Strategic Determinants." Papers in Regional Science 80(3): 317-336.

Mitchell, J.W. 2015. "Predicting Craft Beer Trends in 2015." www.craftbeer.com/craft-beermuses/predicting-craft-beer-trends-2015 (accessed June 15, 2015).

Porter, M.E. 1980. Competitive Strategy. New York, NY: The Free Press. 
1990. The Competitive Advantage of Nations. New York, NY: The Free Press.

Redding, J. 2013. "2012 Industry Review." The New Brewer 30(3): 86.

Scherer, F.M. 1979. "The Welfare Economics of Product Variety: An Application to the Readyto-eat Cereals Industry." Journal of Industrial Economics 28(2): 113-134.

Schmalensee, R. 1978. "Entry Deterrence in the Ready-to-eat Breakfast Cereal Industry." Bell Journal of Economics 9(2): 305-327.

Tremblay, C.H., and V.J. Tremblay. 1996. "Firm Success, National Status, and Product Line Diversification: An Empirical Examination." Review of Industrial Organization 11(6): 771-789.

Tremblay, V.J., and C.H. Tremblay. 2005. The U.S. Brewing Industry: Data and Economic Analysis. Cambridge, MA: The MIT Press.

Watson, R. 2009. "Product Variety and Competition in the Retail Market for Eyeglasses." The Journal of Industrial Economics 57(2): 217-251. 